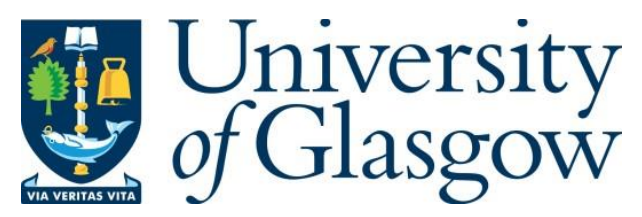

Fontaine, S. J. (2018) The role of reflective practice in professional development. Veterinary Nurse, 9(7), pp. 340-347.

There may be differences between this version and the published version. You are advised to consult the publisher's version if you wish to cite from it.

http://eprints.gla.ac.uk/171510/

Deposited on: 18 October 2018

Enlighten - Research publications by members of the University of Glasgow http://eprints.gla.ac.uk 


\section{The role of reflective practice in professional development}

\section{Introduction}

There are many definitions of reflective practice (RP) in the literature, however in general terms it is when an individual thinks critically about an event in order to understand how it made them feel, why they behaved the way they did, what other factors influenced the event, and what they might have done differently. This process allows the individual to learn from their experiences and can result in changed perception and behaviour (Bulman, 2013).

Individuals can reflect on positive or negative experiences, or on the mundane habitual aspects of practice (Asadoorian \& Batty, 2005). There are many published benefits of performing RP. A concept analysis of 50 published works revealed that nurses who undertook reflection had a heightened understanding of self and practice, improved ability to provide excellent patient care, improved communication with colleagues and patients, and enhanced self-directed learning (SDL) and professional maturity (Tashiro et al, 2013). This literature review aims to explore in more detail these latter benefits of RP and how they can be applied to support the professional development of Registered Veterinary Nurses (RVNs).

\section{Continuing professional development}

The science of veterinary medicine is constantly evolving with an ever-growing body of knowledge and a rapid rate of technological change. In addition, there are regulatory and societal expectations that veterinary nurses are professionally accountable. Consequently, RVNs are required to engage in a process of life-long learning (LLL), and personal and professional development in order to maintain and improve professional ability (Branscombe \& Lumbis, 2010). One way of evidencing this process is for RVNs to undertake continuing professional development (CPD) throughout their careers (Royal College of Veterinary Surgeons (RCVS), 2018a).

The RCVS (2018a) defines CPD as:

"the process of continually maintaining, improving and broadening your skills and knowledge, as well as developing personal qualities which help to ensure you remain professionally competent."

CPD is strongly bound to professional activity and participation may be intrinsically and extrinsically motivated (Cole, 2000; Dale, Pierce \& May, 2010; Friedman \& Woodhead, 2008):

- It improves an RVNs technical and scientific knowledge (Intrinsic)

- It improves an RVNs ethical and personal capacity (Intrinsic)

- It is integral to the development of professional status and fulfils professional responsibilities (Intrinsic)

- It is a key way that RVNs can develop their specialisms and their careers by allowing them to improve their performance in their current role, to take on new roles, and to improve career prospects and progression with their current, or a new employer (Extrinsic)

- It helps maintain quality of professional service, thereby reassuring the recipients and purchasers of those services (Intrinsic)

- It improves the possibility of increased earning potential (Extrinsic) 
There are also social motivators for participating in CPD including the opportunity to meet friends, have fun with colleagues, be able to network with others, and be able to exchange ideas with peers (Dale, Pierce \& May, 2010).

Regardless of the motivation, CPD participation requires a commitment to SDL, where one takes the initiative to identify their learning needs and how they will address them (Jennings, 2007). SDL is an important element of LLL and can have positive effects on practice including improved practical skills in critical thinking, understanding, retention/recall, and decision-making (Jennings, 2007). There can also be improvements in personal attributes including increased motivation, satisfaction, confidence and competence (Jennings, 2007).

\section{The current model of CPD}

CPD is mandatory for all RVNs, and requires participation in a minimum of 45 hours over 3 years. The completed activities are logged as hours in a CPD record, which is used as evidence for professional registration (RCVS, 2018a). CPD is traditionally undertaken following the input-based CPD model. This model acknowledges that an RVN has undertaken some sort of prescribed didactic CPD activity, usually by attending a conference or lecture-style meeting. It does not require them to reflect upon what learning has taken place, nor how this can be applied to their practice (Friedman \& Woodhead, 2008; Wallace \& May, 2016).

It is argued that merely undertaking input-based CPD does not necessarily make the individual competent, nor lead to improvements in professional practice (Friedman \& Woodhead, 2008; McDougall, Epstein \& Highet, 2017). In addition, the input-based CPD model does not readily encompass learning through experience and action, which is considered to be an important component of both adult learning and LLL (Cole, 2000). Neither does this model encourage reflection, which can lead to deeper learning, self-awareness, and enhanced personal and professional development (Jayatilleke \& Mackie, 2012).

\section{An alternative model of CPD}

CPD that moves away from the traditional didactic lecture model to that which encourages a more interactive approach is now considered preferable (Friedman \& Woodhead, 2008). An alternative outcome-based CPD model has therefore been proposed which encourages deeper learning through exposure to mixed activities, as well as opportunities to practice skills, to close the theory-practice gap, and to reflect on current and desired practice (Wallace \& May, 2016). This model importantly encourages individuals to analyse their own unique learning needs, and to identify or create suitable learning opportunities (Cole, 2000). As such, this is the ideal model to assist with SDL. Within an outcome-based model, one is also required to assess whether the activity satisfied their specific learning needs or not (Cole, 2000). This final step ensures that the value of the CPD undertaken is considered, and whether further learning activities are required.

An outcomes-based CPD cycle proposed by Friedman \& Woodhead (2008) incorporates the stages of planning, action, outcomes, and reflection. Outcomes include what change in knowledge and behaviour occurred as a result of the learning activity, and what the results of these were to the patients and the practice (Friedman \& Woodhead, 2008). The RCVS, in recognition of the weaknesses of input-led CPD, has proposed the implementation of a similar outcome-based 
approach to CPD and LLL for RVNs which encompasses a cycle of planning, doing, recording and reflecting (Fig. 1; RCVS, 2016a).

\section{The role of reflection in outcome-based CPD}

Brigley et al (1997) describe the role that RP plays in CPD. Although a dated article, the reasons given are all currently applicable to RVNs:

- Promotes the development of self-awareness and critical thinking about practice.

- Relates theory and practice by offering a systematic way of educating professionals in their everyday work.

- Enhances professionalism by placing responsibility with the individual practitioner to be open-minded and committed to an enquiry-based approach.

- Places problems faced by practitioners in a wider organisational and social context.

- Facilitates multidisciplinary interaction as they negotiate, plan, and implement CPD.

The RCVS outcome-based CPD model only requires formal reflection to occur in the final stage; however this author would argue that reflection forms an integral part of all four stages of the CPD cycle.

\section{Stage 1: Planning}

The first step in the RCVS (2016a) CPD cycle is to plan learning needs and objectives by reflecting on practice (Friedman \& Woodhead, 2008). RP helps achieve better understanding of what you need to know, or be able to do, through exploring activities or significant events at work. Brigley et al (1997) recommend keeping a diary or journal to record and comment on these activities and events. Structuring this diary around a model of reflection can help one critically explore events more deeply. A simple model for this purpose is Rolfe's (2001) model of reflection which consists of three main questions which are supplemented by additional sub-questions (Fig. 2). The three main questions are:

1. What?

2. So what?

3. Now what?

The first question encourages one to describe the event in detail and consider the consequences of the event. The second question prompts one to consider more critically the impact the event had, and what they might have done differently. The final question helps one to formulate an action plan that identifies additional skills, knowledge, or changes to practice that might be required. These are essentially an individual's learning needs, and can be transferred to a development plan to create specific objectives (RCVS, 2016a).

RP can also be used in a group context in the planning stage to reflect upon events that may help to identify learning needs for both individuals and the wider practice team. There are a variety of opportunities where RP can be used in this context including routine practice meetings, appraisal meetings, critical incident analyses, action learning sets, practice improvement meetings, mentor meetings, journal club, rounds/handovers, and morbidity and mortality rounds (Driscol \& Teh, 2001). 
Self-assessment (SA) also forms an important part of the initial planning stage. SA has been described as an active process of developing an awareness of personal learning needs in order to guide participation in suitable learning activities (Asadoorian \& Batty, 2005). The RCVS advises that RVNs undertake regular SA and appraisals to plan their professional development and address any performance issues (RCVS, 2018a). Conducting SA can motivate individuals to develop their professional learning in order to implement the changes needed to enhance or improve their performance. It can also help direct individuals to their required professional learning in a more efficient and effective manner (Asadoorian \& Batty, 2005). Completing CPD in an ad hoc fashion may result in wasting time and money on activities that did not meet one's needs (RCVS, 2018a). SA and planning ahead ensures learning opportunities are effective as one undertakes focussed activities. This makes it more attractive for employers to fund the CPD activity, as it is clear what the benefits to an individuals practice would be.

Reflecting on events in practice whilst performing SA helps one to identify weaknesses, and consequently to set appropriate learning goals. It also helps one to identify strengths, and encourages one to set challenging learning goals which pushes one's knowledge rather than just reiterates what is already known (Eva and Regehr, 2005). There are a variety of tools of reflection that can help an individual to undertake SA include skills evaluation checklists, SWOT analysis, professional development planning (PDP), and SMART objectives. Table 1 describes the use of these tools in more detail.

The ability to recognise one's strengths and weaknesses is an important component of SDL, and a criticism of SA is that it is easy for individuals to either over-or underestimate their competence in certain areas (Eva et al, 2004). In order to address this, it has been recommended that prior to actioning one's identified learning needs, a CPD plan should be discussed with others (for example line manager, mentor, clinical coach, peers). This will help the individual to gain additional viewpoints, which may in turn help eliminate subjective distortions, and will help broaden learning priorities to include wider organisational requirements (Brigley et al, 1997).

The final consideration to undertake in the planning stage is for the RVN to reflect upon their job role and to select CPD topics that are relevant to this, whilst also being mindful of the fact that it is important to venture outside of one's 'comfort zone' every so often (Branscombe and Lumbis, 2010).

\section{Stage 2: Doing}

There are a range of different CPD activities that may be undertaken to meet the RVNs identified learning needs (Table 2). Ideally the individual would reflect upon which specific activities may best suit their preferred learning style, their lifestyle, and the level of support they are likely to receive from their employer (e.g. funding of activity, time off work to attend).

\section{Stage 3: Recording}

Upon completion of the CPD activity a record should be completed, to include evidence such as certificates or notes (RCVS, 2016a). Keeping a reflective diary to record an exploration of the learning undertaken is ideal for this situation (Brigley et al, 1997). The diary can be structured around a model of reflection in order to more deeply identify the learning and changes to behaviour 
that have occurred. Reflection on the overall quality of the learning experience is also useful, including whether the activity fitted with the individuals preferred learning style, and whether there were any barriers to learning that need considered for the future (Brigley et al, 1997).

\section{Stage 4: Reflecting}

The final stage of any CPD activity is to reflect upon the impact of the learning activity and whether it met the RVNs objectives in their development plan (RCVS, 2016a). The individual should reflect upon the specific things they have learned, and how this learning aligns to their professional regulatory frameworks, their current and desired practice, and their professional responsibilities (Brigley at al, 1997).

Within Brigley et al's (1997) CPD cycle, providing feedback on CPD to colleagues is considered important. This can be used as a tool for reinforcing or consolidating the learning that has occurred from participation in the CPD activity. One selects the new, important, or salient points from the information they gathered during the activity, considers how these relate to their existing practice, and determine whether changes to practice based on this new learning should/could occur. This information is then disseminated to their colleagues either through verbal or written form, ideally at multidisciplinary practice meetings. Through discussing how the learning from CPD can be used to guide or influence current practice, individuals are encouraged to participate in evidence-based veterinary medicine (Mann, 2017).

As the learning undertaken through outcome-based CPD is often multidimensional, the change in knowledge or skills that have resulted from the CPD activity should be measured in some way. Outcomes can be measured in the context of changes to professional behaviour, and the impact these changes have had on the clients, patients, and the employer (Friedman \& Woodhead, 2008; Wallace \& May, 2016). Measurements may be subjective, for example critical RP using a model of reflection, completion of self-assessment tools, or gathering feedback from colleagues or clients. Measurements may also be objective, for example conducting clinical, process, or financial audits, or reviewing the results of formal assessment. Determining the outcome of CPD can be achieved through reflecting upon exactly what you are doing differently now to before the learning was undertaken. The exact things you choose to reflect upon will depend on the topic and type of CPD undertaken, and Table 3 describes some examples. The process of participating in CPD activities and then measuring the outcomes helps the RVN to meet many RCVS clinical governance recommendations (RCVS 2018b). However, it is vital to note that measuring outcomes can be difficult, and is time-consuming for the individual and/or practice (Cole, 2000; Wallace \& May, 2016).

Undertaking RP in this final stage of an outcomes-based CPD cycle would undoubtedly include identification of the individual's current learning needs, and would help prioritise future CPD activities (Brigley et al, 1997). At this point the whole CPD cycle would repeat again.

\section{The challenges of forcing reflection}

A consultation with the veterinary profession to the proposed RCVS outcome-based CPD model revealed that despite over $50 \%$ of the 3,357 respondents agreeing with the model, less than half agreed that there should be a requirement to perform reflection on the learning activities undertaken (RCVS, 2016b). This response reveals a reticence to RP within the profession, perhaps 
due to a lack of understanding about what this process is and how important it is within learning (RCVS, 2016b). Concerns about the requirement for healthcare professionals to reflect on CPD have also been made, which raises some important questions about forcing reflection in this context (Macdougall, Epstein, and Highet, 2016):

- Are the reported benefits of RP lost as a consequence?

- Does it force the reluctant to become engaged in the process, or to merely undertake a boxticking exercise?

- Does it merely encourage individuals to reflect by rote, rather than truly critically exploring the learning activity in order to undertake the deeper learning required for associated behaviour changes to occur?

As the veterinary profession is currently not required to undertake formal reflection on CPD activities, the answers to these questions will only become apparent over time if an outcomes-based CPD model is implemented by the RCVS.

In addition to the concerns regarding forced reflection, several other concerns about the proposed new CPD requirements were also identified (RCVS, 2016b):

- It would add stress and pressure to already busy/overworked professionals.

- It would be difficult to maintain a good work/life balance.

- The process is too bureaucratic, involving too much paperwork.

Other barriers to veterinary surgeons participation in CPD were identified by Dale, Pierce \& May, (2010), and it would be assumed that similar barriers for RVNs exist. These include:

- Inability of individuals to identify/admit to learning needs.

- Lack of available/interesting CPD

- Lack of motivation (no obvious benefits, dislike travelling, not held at convenient times).

- Lack of employer support (lack of funding, or time to attend).

It is important that the profession finds ways to overcome these barriers, and highlights the need for education in RP and SA techniques, and in employers supporting their staff to participate in CPD activities.

\section{Conclusion}

The requirement for RVNs to undertake CPD is regarded integral to the ongoing development of their profession. In response to concerns that engagement in the traditional input-based model of CPD does not guarantee competence, the RCVS (2016a) has proposed an outcome-based model. This would be better aligned to the needs of the adult and experiential learner, as individuals are able to explore their own learning needs, to self-direct their learning experiences, and to participate in learning activities that are directly applicable to their own work contexts (Macdougall, Epstein \& Highet, 2016).

Reflective practice is considered an important component of modern CPD activities as it is at the centre of professional learning (Schön, 1983). Reflection helps encourage deeper learning, and can 
234 facilitate the individual learning from their own experiences, and in developing greater self-

235 awareness and self-examination (Kim et al, 2010).

236 Despite the concerns raised by the veterinary profession about the requirement to undertake RP

237 throughout the CPD cycle, and the wider concerns raised about forcing professional reflection, this

238 author would argue the potential benefits outweigh the concerns. A recent qualitative study

239 investigating opinions of early-career and mid-late career nurses by Price and Reichert (2017)

240 revealed that access to training and education were directly linked to increased career satisfaction.

241 This is an important finding as it directly relates to retention of the workforce. This study also

242 revealed that an employer that invests in CPD opportunities, either through providing the time or

243 finances to undertake the activities, was considered vital to ensuring their nurses undertook

244 continuous growth and provided optimal patient care. It would be hoped that similar outcomes

245 would be true for RVNs. Through participating in CPD, RVNs are ensuring they are behaving in a

246 manner which aligns directly to the RCVS Code of Professional Conduct for Veterinary Nurses which,

247 in turn, helps to improve the industry and public perception of their profession (RCVS, 2018b). 


\section{References}

1. Asadoorian J, Batty H (2005) An evidence-based model of effective self-assessment for directing professional learning. Journal of Dental Education 69(12): 1315-1323

2. Brigley S, Young Y, Littlejohns P, McEwan J (1997) Continuing education for medical professionals: a reflective model. Postgraduate Medical Journal 73: 23-26

3. Branscombe L, Lumbis $R$ (2010) Evaluating the need for continuing professional development (CPD). The Veterinary Nurse 1(1): 4-11

4. Bulman, C (2013) Ch 6. An Introduction to Reflection. In: Bulman C, Schutz S, eds. Reflective Practice in Nursing. $5^{\text {th }}$ Edn. John Wiley \& Sons Ltd, Oxford: 15-35

5. Cole $M(2000)$ Learning through reflective practice: a professional approach to effective continuing professional development among healthcare professionals. Research in PostCompulsory Education 5(1): 23-38

6. Dale V, Pierce SE, May SA (2010) The importance of cultivating a preference for complexity in veterinarians for effective lifelong learning. Journal of Veterinary Medical Education 37(2): 165-171

7. Driscoll J, Teh B (2001) The potential of reflective practice to develop individual orthopaedic nurse practitioners and their practice. Journal of Orthopaedic Nursing 5: 95-103.

8. Eva KW, Cunnington JP, Reiter HI, Keane DR, Norman GR (2004) How can I know what I don't know? Poor self-assessment in a well-defined domain. Advances in Health Science Education. Theory and Practice 9(3): 211-224

9. Eva KW, Regehr G (2005) Self-assessment in the health professions: A reformulation and research agenda. Academic Medicine 80(10): S46-S54

10. Friedman A, Woodhead S (2008) Approaches to CPD measurement. [Online]. Bristol: Professional Associations Research Network. [Accessed 09 May 2018]. Available from http://www.iaesb.org/system/files/meetings/files/3629.pdf

11. Jayatilleke N, Mackie A (2012) Reflection as part of continuous professional development for public health professionals: a literature review. Journal of Public Health 35(2): 308-312

12. Jennings SF (2007) Personal development plans and self-directed learning for healthcare professionals: are they evidence based? Postgraduate Medical Journal 83:518-524

13. Kim HS, Clabo LML, Burbank P, Martins MLD (2010) Ch 8. Application of Critical Reflective Inquiry in Nursing Education. In: Lyons N, ed. Handbook of Reflection and Reflective Inquiry: Mapping a Way of Knowing for Professional Reflective Inquiry. Springer US, New York: 159172

14. Macdougall C, Epstein M, Highet L (2017) Continuing professional development: putting the learner back at the centre. Archives of Diseases in Childhood. Education and Practice Edition 102: $249-253$

15. Mann A (2017) Evidence-based veterinary medicine (EBVM) - how nurses can get involved. The Veterinary Nurse 8(7): 353-357

16. Price $S$, Reichert $C$ (2017) the importance of continuing professional development to career satisfaction and patient care: Meeting the needs of novice to mid- to late-career nurses throughout their careers span. Administrative Sciences 7(17): 1-13

17. Rolfe G, Freshwater D, Jasper M (2001) Critical Reflection in Nursing and the Helping Professions: A User's Guide. Palgrave MacMillan, Basingstoke 
18. Royal College of Veterinary Surgeons (2016a) RCVS Review of Continuing Professional Development. [Online]. Available from https://www.rcvs.org.uk/document-library/rcvs-cpdreview-2016-proposals/rcvs-cpd-consultation-proposals-june-2016.pdf. [Last accessed 23 May 2018]

19. Royal College of Veterinary Surgeons (2016b) CPD Policy Working Party Response to Outcomes-Based CPD Consultation. [Online]. Available from https://www.rcvs.org.uk/document-library/cpd-policy-working-party-response-to-cpdconsultation/cpd-wp-response-to-cpd-consultation-nov16.pdf. [Last accessed 23 May 2018]

20. Royal College of Veterinary Surgeons (2018a) Continuing Professional Development (CPD). [ONLINE]. Available from https://www.rcvs.org.uk/lifelong-learning/continuing-professionaldevelopment-cpd/. [Last accessed 09 May 2018]

21. Royal College of Veterinary Surgeons (2018b) Code of Professional Conduct for Veterinary Nurses. [ONLINE]. Available from https://www.rcvs.org.uk/setting-standards/advice-andguidance/code-of-professional-conduct-for-veterinary-nurses/\#thercvs. [Last accessed 23 May 2018]

22. Schön DA (1983) The Reflective Practitioner: How Professionals Think. Basic Books/Harper Collins, San Francisco

23. Tashiro J, Shimpuku Y, Naruse K, Matsutani M, Matsutani M (2013) Concept analysis of reflection in nursing professional development. Japan Journal of Nursing Science 10: 170-179

24. Wallace S, May SA (2016) Assessing and enhancing quality through outcomes-based continuing professional development (CPD): a review of current practice. Veterinary Record 179: 515-520 